Research Article

\title{
Joint Dynamic Innovation and Pricing Decisions for the ODM Supply Chain
}

\author{
Xin Wang \\ School of Economics and Management, Shanghai Polytechnic University, Shanghai 201209, China \\ Correspondence should be addressed to Xin Wang; wangxinreport@126.com
}

Received 3 April 2021; Accepted 19 July 2021; Published 27 July 2021

Academic Editor: Kebing Chen

Copyright (c) 2021 Xin Wang. This is an open access article distributed under the Creative Commons Attribution License, which permits unrestricted use, distribution, and reproduction in any medium, provided the original work is properly cited.

\begin{abstract}
More and more companies in the supply chain choose the cooperation mode of original design and manufacturing (ODM). This paper investigates the problems of the joint design innovation and pricing strategies for the ODM supply chain by considering the impact of the dynamic of quality level on market demand. First, applying differential game theory, optimal strategies for design innovation, and pricing under decentralized and centralized scenarios are obtained. At the same time, the optimal strategies under the two decision-making scenarios are compared and analyzed. Second, a two-part tariff contract is introduced to coordinate the decentralized ODM supply chain. Finally, we further establish a Nash bargaining model among members of the supply chain. It is found that, in a centralized system, the design innovation efforts, product quality levels, and supply chain profits in the decentralized decision scenario are lower than that in the centralized decision scenario, but the selling price relationship in both scenarios depends on the parameters of the operating system.
\end{abstract}

\section{Introduction}

Design innovation, manufacturing, and brand promotion exist in the electronic industry, in which electronic companies always expect to maintain their dominant position. Due to the increasing complexity of the operation of the electronic industry, more and more attention has been paid to the operation and supply chain management researchers. Quality, however, is a critical success factor in electronics supply chains [1]. Today, electronic brands are under pressure from rivals to quickly bring high-quality new products to the market. This is especially true in the electronics industry, where the product life cycle has been greatly shortened. Faced with fierce competition and changing nature, the electronics industry began to introduce outsourcing to achieve low cost and short delivery times. Under the mechanism of knowledge spillover of service outsourcing, enterprises can gain advantages by maintaining core competitiveness and reducing costs [2]. There are essentially two business models for service outsourcing: The first model is a contract design and manufacturing $(\mathrm{CDM})$ company that obtains the brand's conceptual design contract, and then the two companies collaborate on physical design and development [3]. The second model is original design and manufacturing $(\mathrm{ODM})$, in which OEM outsources the entire design and development process to ODM and purchases "off-theshelf" products that are completely designed and manufactured by ODM. Since the design and manufacturing of goods are finished by the original design manufacturer, the ODM strategy provides opportunities for manufacturability design. Design methods for manufacturability lead to product designs that are easy to cost-effective. According to a study, $75 \%$ of the manufacturing cost of a product is determined by the design process of goods [4]. As labor acquires design skills in countries such as China at lower labor costs, ODM strategies will become increasingly popular [5]. ODM outsourcing activities are prevalent in the electronics and computer industry, where a handful of large ODMs dominate. For example, Quanta Computer, being the largest one, supplied $33 \%$ of the world's total production of notebook PCs in 2007. Quanta's major 
customers include Apple, Dell, Gateway, Hewlett-Packard, Sony, etc. All these industrial examples show that the ODM business model has become a trend in the electronics supply chain.

Although ODM is becoming more and more popular, at the same time, people have a certain degree of concern and reservations about the ODM business model in the supply of electronic products. This paper focuses on issues specific to design outsourcing in the electronics industry. For household appliances, their quality refers to the energy efficiency level, which measures the relationship between the efficiency of an electrical product using energy and its volume. The sales of home appliances are not only affected by the price but also by the quality level of the products, and the quality level depends largely on the energy efficiency level of the home appliances. Residents can choose an effective way to reduce carbon emissions, that is, to purchase energy-efficient products with less pollution [6]. Given the situation above, China uses energy labels to rank products of the same type according to efficiency categories so as to inform consumers of purchase decisions. Generally speaking, the higher the energy efficiency of a product, the higher its market value. Design innovation is one of the strategies commonly adopted by manufacturing enterprises.

However, technological advance simultaneously lifts the energy efficiency standards. The minimum energy performance standards, for example, are usually updated every 3-4 years [7], with each update typically increase by about $10 \%$ over the previous level. This may result in that some products with low energy efficiency levels are no longer available and that the products of level 1 degrade to level 2 now, which can be regarded as the decay of energy efficiency level over time. The quality level of a product can not only be improved through design innovation but also decay with the passage of time. Therefore, describing changes in quality levels in a dynamic setting is closer to this reality.

In the home appliance industry, as the ODM relationship between suppliers and brands is more stable, the success of enterprises on this channel requires the joint efforts of both parties. The brand outsources the product design to the supplier, focusing on its main competitiveness: branding and pricing, while the supplier is responsible for product design and product manufacturing. The home appliance supplier requires knowing how much demand is created through the campaigns, while the brand needs the home appliance supplier to be assured of the product quality and the produced amounts. Both the supplier and the brand in the ODM supply chain will inevitably conflict because the two players of the ODM supply chain have different goals. The brand's goal is to increase demand through marketing while the supplier tries to minimize product manufacturing costs. In other words, the marketing of brand makers will generate cost and revenue while creating demand, while the operation of manufacturers tries to control cost, so the conflict among the channel members of the ODM supply chain is inevitable. In the rest of this article, for convenience, design innovation efforts will be used to refer to all outsourcing activity costs, including product design and product manufacturing.
Our research is motivated by the actual industrial practice in the ODM supply chain. The success of highquality products needs the joint efforts of the channel members, and the dependence between the supplier and the brand is becoming stronger and stronger. However, it is not clear how the dynamics of product quality level affect the joint pricing and design innovation decisions of players. Design innovation effectiveness refers to using less design investment to produce the same quality level of product [8], which is closely aligned with operations management. In the overall profit maximization model, this article combines design innovation and price in an attempt to provide assistance for the coordination of suppliers and brands in the ODM supply chain. In addition, some scholars pointed out that traditional fixed wholesale price contracts often fail to achieve coordination in the ODM supply chain $[3,9,10]$, which constitutes the second research motivation of this paper, in which a novel contract is introduced to coordinate the ODM supply chain.

In this paper, we aim to address three research questions (RQs) as follows:

RQ1: What are the optimal dynamic pricing and innovation strategies for the ODM supply chain?

RQ2: How does the design effectiveness of products affect the solutions?

RQ3: How to design a contract to perfectly coordinate the decentralized supply chain in a dynamic setting?

This paper considers a monopoly supply chain model consisting of a single manufacturer and a single brand. They manage a single product in the market under the ODM strategy. The manufacturer is responsible for the design and manufacture of the product and then sells the finished goods to the end customer through the brand that controls the sales price. The quality level of goods declines over time, which is improved by the manufacturer and has a positive contribution to market demand. Differential equations are used to model the dynamic evolution of quality levels, and the effects of price and quality levels on market demand are described. Using optimal control theory, the design innovation and pricing strategies of players in the centralized and decentralized scenarios are derived. The optimal design innovation and pricing strategies in the two scenarios are compared. Finally, an illustrative example is provided to illustrate the impacts of the design effectiveness and operational inefficiency onto the feasible region of the corresponding contract.

The rest of the paper is organized as follows. Section 2 reviews the related literature. The symbols and assumptions of the models are described in Section 3. Sections 4, 5 explore the corresponding solutions for centralized and decentralized scenarios and then investigate the relationships of the solutions between centralized and decentralized cases. Section 6 designs a two-part tariff contract to coordinate the supply chain under the ODM strategy. Section 7 provides numerical results and sensitivity analysis. Finally, Section 8 concludes the paper with general remarks and future research directions. All of the technical proofs are relegated to the appendix. 


\section{Literature Review}

In this section, we review the related literature. This paper is related to two aspects: service outsourcing in supply chain management and supply chain quality management.

\subsection{Service Outsourcing in Supply Chain Management.} The first stream concentrates on service outsourcing for the supply chain. Service outsourcing activities in the supply chain are mainly divided into two categories: product manufacturing and product design innovation. The challenges and problems in outsourcing practice have attracted the wide attention of academia [9-15]. For example, Plambeck and Taylor [11] studied the impact of service outsourcing on innovation in the supply chain. Iyer et al. [12] considered a supply chain, in which OEM outsources all manufacturing functions of its products to contract manufacturers. Wang and Shin [9] found that revenue sharing contracts can coordinate the static ODM supply chain, whereas the wholesale price contract cannot achieve that coordination goal. Wang et al. [15] pointed out that design outsourcing is an important part of ODM services. Shen et al. [10] pointed out that if the wholesale price contract is adopted, the brand will outsource manufacturing services to the supplier. Among the studies mentioned above, the work of Shen et al. [10] is closest to our paper. Shen et al. [10] investigated the impact of design outsourcing on the fashion supply chain and compared the impact of service outsourcing on the performance of the supply chain. The results show that when a supplier deals with a brand through a wholesale price contract, the supplier has no incentive to invest in innovation under the ODM strategy. This finding is similar to our paper, where the wholesale price cannot coordinate the supply chain under the ODM strategy. This paper extends the investigation of Shen et al. [10] to a dynamic setting, of which the evolution of the product's quality level is embraced. Our focus point is how the dynamic of quality level for the product affects pricing and design innovation effort decisions. Specifically, the quality level of the product can not only be improved through design innovation but also decay with the passage of time. Moreover, interestingly, the designed contract of this paper can effectively coordinate the ODM supply chain so that the channel profit under the decentralized scenario can reach the centralized counterpart under the ODM strategy.

2.2. Supply Chain Quality Management. The second stream focuses on supply chain quality management. In many industries (e.g., electronics, aerospace, automotive, computer, and fashion), suppliers and brands must work together to improve their product quality. The impetus for the improvement of product functional performance comes from the brand's desire to develop the market with high-quality products. Ouardighi and Kogan [16] studied the cooperation between brands and suppliers, focusing on the impact of product design on product quality. A study by Liu et al. [17] suggested that design innovation investment can improve the quality of goods, which positively affects the goodwill. It is well known that the degree of coordination among supply chain members may affect supply quality management [18]. In the bilateral monopoly system, Economides [19] found that the double marginalization effect has a negative effect on the quality of goods. The supply chain under noncooperation will produce a loss of efficiency. Both in the literature and practice, contracts are widely used to provide incentives for the supply chain members to achieve channel coordination [20]. In particular, buyback contracts [21], revenue sharing contracts [22], and profit-sharing contracts [23] are commonly employed in outsourcing businesses. Other coordination contracts are like gain sharing contract [24], cost sharing contract [25], supply contract [26], quantity compensation contract [27], linear margin contract [28], advance-purchase contract [29], inventory subsidizing contract [30], two-part price contract [31], and supply option contract [32]. The prior literature did not explore the joint effects of time and design innovation on the quality of the products. In this paper, the quality level of goods declines over time, which is improved by the innovation efforts of the manufacturer and has a positive contribution to market demand. We examine the cooperation between a brand and a supplier to improve a product's quality by using a novel coordinating contract. This contributes to supply chain quality management.

The contributions of this paper can be positioned as follows. First, this work grasps the reality that the quality level of a product not only experiences a decay with time but also is pulled up by the design innovation of the manufacturer. Second, we make a technical contribution by solving the Hamiltonian-Jacobi-Bellman equation for this case and offer new managerial insights into joint design innovation effort and pricing decisions by considering quality level. Third, the analytic results show that the wholesale price contract fails to realize the coordination of the ODM supply chain, whereas we design a two-part tariff contract, in which the wholesale price is a function of the quality of goods, can effectively coordinate the supply chain under the ODM strategy. To the best of our knowledge, this paper is the first one to study the joint optimal innovation and pricing decisions for the ODM supply chain in a dynamic setting.

\section{The Model}

This paper considers an ODM supply chain model consisting of a manufacturer and a brand. The manufacturer is responsible for the design and manufacture of the goods and then sells the products to end consumers through the brand that sets the selling price. The quality level of the product drops over time and is improved by the design efforts of the manufacturer. This paper aims to propose new design innovation and pricing under the wholesale contract.

Generally speaking, from a perspective of the finished product, the design efforts aim to raise the quality level of the product, which is mainly reflected by employing excellent designers to design the most novel styles, installing special equipment to satisfy process innovation for a particular item. Instantaneous investment in product innovation can 
improve the cumulative product quality $[33,34]$. The dynamics of the quality level is given by

$$
q^{\prime}(t)=\varepsilon I(t)-\phi q(t),
$$

where $q(t)$ is the quality level of product with $q(0)=q_{0}$ and $\phi>0$ represents the deteriorating rate. The variable $I(t)$ states the design innovation investment of manufacturers on the quality level. The parameter $\varepsilon>0$ is the innovation efficiency coefficient.

If the manufacturer's design efforts enhance the quality level of the product, the design innovation cost of the manufacturer is negatively affected by the quality improvement of goods. As it is common in the quality improvement literature $[17,35-38]$, the design innovation cost $C_{I}(t)$ is introduced as follows:

$$
C_{I}(t)=\frac{1}{2} k I^{2}(t)
$$

where $k$ is the investment cost parameter.

While product design innovation improves the quality level of products, it also increases extra costs in the production process, such as labor costs and safety costs [39]. Therefore, we assume that the production cost of goods as follows:

$$
C_{V}(t)=c_{0}+c_{1} q(t)
$$

where $C_{V}(t)$ is the total production cost. $c_{0}$ represents the initial unit production cost which means a fixed production cost. The parameter $c_{1}$ represents the marginal production cost due to energy efficiency level improvement, herein it is called operational inefficiency coefficient. This linear increasing cost function has been taken by many researchers, including Vörös [33] and Giovanni [34].
Usually, consumers tend to buy products with high quality and low prices. Ouardighi et al. [16] believed that product demand is determined by both price and nonprice factors and can be assumed to be a separable linear form of these two factors. Other similar demand function forms can be found in the literature $[40,41]$. Drawing on the description of the demand function in the existing literature, considering the factors of quality and price, the market demand $D(t)$ is assumed as follows:

$$
D(t)=a-b p(t)+\mu q(t) .
$$

The positive parameter $a$ is the fixed market size and the positive parameter $b$ represents the price sensitivity of demand. The methods proposed by Chen and Plambeck [42], Şen and Zhang [43], and Araman and Caldentey [44] can be employed to estimate $a$ and $b$ in formula (4). The positive parameter $\mu$ reflects the promotional effect of the quality on market demand.

The manufacturer and brand are denoted by the subscript " $M$ " and "B", respectively. Assuming an infinite time horizon, the objective functions of both players are given by

$$
\begin{aligned}
\max \Pi_{M} & =\int_{0}^{\infty} e^{-r t}\left\{\left[\omega(t)-C_{V}(t)\right] D(t)-C_{I}(t)\right\} \mathrm{d} t, \\
\max \Pi_{B} & =\int_{0}^{\infty} e^{-r t}\{[p(t)-\omega(t)] D(t)\} \mathrm{d} t,
\end{aligned}
$$

where $r$ is a positive discount rate, and $\omega(t)$ is the wholesale price charged by the manufacturer to the brand.

Thus, a differential game between the manufacturer and the brand of the ODM supply chain is developed as follows:

$$
\begin{aligned}
\max _{\omega(t), I(t)} \Pi_{M} & =\int_{0}^{\infty} e^{-r t}\left\{\left[\omega(t)-c_{0}-c_{1} q(t)\right] D(t)-\frac{1}{2} k I^{2}(t)\right\} \mathrm{d} t, \\
\max _{p(t)} \Pi_{B} & =\int_{0}^{\infty} e^{-r t}\{(p(t)-\omega(t)) D(t)\} \mathrm{d} t, \\
\text { s.t. } q^{\prime}(t) & =\varepsilon I(t)-\phi q(t), q(0)=q_{0} .
\end{aligned}
$$

In (6a)-(6c), we depict a Stackelberg differential game with one state variable $q(t)$, two players, and three control variables, $\omega(t), I(t)$, and $p(t)$.

\section{The Optimal Strategies under the Centralized Scenario}

The centralized decision means that the manufacturer and the brand are integrated as a whole system. The goal of the centralized scenario is to derive the optimal design innovation $I(t)$ and selling price $p(t)$, while maximizing the supply chain's profit. Let the superscript " $C$ " signify the centralized decision. The centralized decision can achieve the best results, so it can be used as a benchmark. The ODM supply chain's objective function is formulated as

$$
\begin{aligned}
P 1: & \max _{p(t), I(t)} \Pi_{S C}^{C}=\int_{0}^{\infty} e^{-r t}\left\{\left[p(t)-C_{V}(t)\right] D(t)-C_{I}(t)\right\} \mathrm{d} t \\
\text { s.t. } \quad q^{\prime}(t) & =\varepsilon I(t)-\phi q(t) .
\end{aligned}
$$

To obtain the optimal dynamic design innovation and price policies, we denote $V_{S C}^{C}(q)$ as the supply chain' value function $[45,46]$, which satisfies the Hamiltonian-Jacobi-Bellman (HJB) equation as 


$$
r V_{S C}^{C}(q)=\max _{p, I}\left\{\left(p-c_{0}-c_{1} q\right)(a-b p+\mu q)-\frac{1}{2} k I^{2}+V_{S C}^{C^{\prime}}(\varepsilon I-\phi q)\right\} .
$$

The following notations are defined to simplify the expression of the mathematical model:

$$
\begin{aligned}
\Omega_{1} & =\sqrt{b k\left[b k(2 \phi+r)^{2}-2 \varepsilon^{2}\left(\mu-b c_{1}\right)^{2}\right]}, \\
f_{1} & =\frac{b k(2 \phi+r)-\Omega_{1}}{2 b \varepsilon^{2}}, \\
f_{2} & =\frac{k\left(a-b c_{0}\right)-\left(\mu-b c_{1}\right)}{r b k+\Omega_{1}}, \\
f_{3} & =\frac{\left(a-b c_{0}\right)^{2}\left[\left(r b k+\Omega_{1}\right)^{2}+2 b k \varepsilon^{2}\left(\mu-b c_{1}\right)^{2}\right]}{4 b r\left(r b k+\Omega_{1}\right)^{2}} .
\end{aligned}
$$

The following proposition characterizes the optimal solutions of players under the centralized decision.

Proposition 1. With centralized decision-making, the equilibrium strategies of the differential game between the manufacturer and the brand are given by

$$
\begin{aligned}
I^{C}(t) & =\frac{\varepsilon}{k}\left(f_{1} q(t)+f_{2}\right), \\
p^{C}(t) & =\frac{a+b c_{0}+\left(\mu+b c_{1}\right) q(t)}{2 b} .
\end{aligned}
$$

Proposition 1 shows that the equilibrium strategies (i.e., design innovation $I^{C}(t)$ and selling price $\left.p^{C}(t)\right)$ are linear and increasing in quality $q(t)$, which indicates that when consumers have a preference for high-quality products, decision makers will increase design efforts and price by improving product quality to maximize profits.

Substituting (10) into the state equation (1) gives

$$
q^{C *}(t)=\left(q_{0}-q_{\infty}^{C}\right) e^{-\eta^{C} t}+q_{\infty}^{C},
$$

where $\eta^{C}=\left(\Omega_{1}^{2}-r^{2} b^{2} k^{2} / 2 b k\left(r b k+\Omega_{1}\right)\right), q_{\infty}^{C}=\left(2 b k \varepsilon^{2}(\mu-\right.$ $\left.\left.b c_{1}\right)\left(a-b c_{0}\right) / \Omega_{1}^{2}-r^{2} b^{2} k^{2}\right)$ referring to the steady-state quality level. Thus, based on Proposition 1, the optimal design innovation $I^{C *}(t)$ and pricing $p^{C *}(t)$ can be presented as the following proposition.

Proposition 2. With centralized decision-making, the optimal design innovation and selling price are as follows:

$$
\begin{aligned}
& I^{C *}(t)=\frac{\varepsilon}{k} f_{1}\left(q_{0}-q_{\infty}^{C}\right) e^{-\eta^{C} t}+I_{\infty}^{C}, \\
& p^{C *}(t)=\frac{\left(\mu+b c_{1}\right)}{2 b}\left(q_{0}-q_{\infty}^{C}\right) e^{-\eta^{C} t}+p_{\infty}^{C},
\end{aligned}
$$

where $I_{\infty}^{C}=(\varepsilon / k)\left(f_{1} q_{\infty}^{C}+f_{2}\right)$ and $p_{\infty}^{C}=\left(a+b c_{0}+(\mu+\right.$ $\left.\left.b c_{1}\right) q_{\infty}^{C} / 2 b\right)$ represent the steady state of design innovation and selling price, respectively.

With the optimal strategies in Proposition 2, the supply chain's profit for the ODM supply chain can be spelled out as follows:

$$
\Pi_{S C}^{C *}=\frac{f_{1} q_{0}^{2}}{2}+f_{2} q_{0}+f_{3} .
$$

From Proposition 2, it can be found that if $\eta^{C}>0$, the quality $q^{C *}(t)$, the design innovation $I^{C *}(t)$, and the selling price $p^{C *}(t)$ can converge to their steady states $q_{\infty}^{C}, I_{\infty}^{C}$ and $p_{\infty}^{C}$, respectively. Then, according to the size relationship of $q_{0}$ and $q_{\infty}^{C}$, as well as other parameters, the brand can choose penetration or skimming strategy. Specifically, the selling price $p^{C *}(t)$ will rise and finally reach the steady state when $q_{0}<q_{\infty}^{C}$, which is denoted as the penetration pricing strategy. On the contrary, the decision makers will implement the skimming pricing strategy when $q_{0}>q_{\infty}^{C}$.

Corollary 1. In the centralized decision, the comparative static analyses for the steady-state strategies are summarized in Table 1.

Corollary 1 shows the comparative static results of ODM supply chain in the centralized scenario. We compare the effect of the key parameters $\left(\varepsilon, \mu, c_{1}\right)$ on steady-state strategies (design innovation, selling price, quality level). It can be observed that $\varepsilon, \mu$, and $c_{1}$ have opposite effects on the steady-state strategies. For example, steady-state innovation effort $I_{\infty}^{C}$ increases in the innovation efficiency coefficient $\varepsilon$ and quality preference sensitivity coefficient $\mu$ but decreases in the operational inefficiency coefficient $c_{1}$. These results indicate that a larger $\varepsilon$ means a higher quality contribution, which can increase innovation input, thereby improving the quality level of goods and allowing higher selling prices. However, the operational inefficiency coefficient $c_{1}$ has a negative impact on the steady-state strategy. A larger $c_{1}$ hinders innovation investment, which ultimately leads to lower quality products and lower selling prices.

From Proposition 2, we also observe that if $q_{0}<q_{\infty}^{C}$, design innovation $I^{C *}(t)$ will increase, whereas the design innovation $I^{C *}(t)$ decreases when $q_{0}>q_{\infty}^{C}$. These results indicate that the brand will reduce costs by reducing design innovation and increase profits when the initial quality is relatively large. However, if the initial quality level of the goods is low enough, there is room for improvement in product quality, so the brand has an incentive to increase profits by increasing investment in innovation. 
TABLE 1: Comparative static results for the centralized decision.

\begin{tabular}{lccc}
\hline Parameters & $I_{\infty}^{C}$ & $p_{\infty}^{C}$ & $q_{\infty}^{C}$ \\
\hline$\varepsilon$ & $\uparrow$ & $\uparrow$ & $\uparrow$ \\
$\mu$ & $\uparrow$ & $\uparrow$ & $\uparrow$ \\
$c_{1}$ & $\downarrow$ & $\downarrow$ & $\downarrow$ \\
\hline
\end{tabular}

Note. $\downarrow$ : decrease; $\uparrow$ : increase.

Note that in Proposition 2, if $q_{0}=q_{\infty}^{C}$, the design innovation and selling price remain constant. The bound on the operational inefficiency coefficient, i.e. $c_{1} \in(0, \mu / b)$, comes from the fact that steady quality level of goods $q_{\infty}^{C}=\left(2 b k \varepsilon^{2}\left(\mu-b c_{1}\right)\left(a-b c_{0}\right) / \Omega_{1}^{2}-r^{2} b^{2} k^{2}\right)$ should remain nonnegative.

Corollary 2. In the centralized decision, the steady-state quality level is decreasing in the operational inefficiency coefficient. Mathematically, $\partial q_{\infty}^{C} / \partial c_{1}>0$.

This result, along with Corollary 1 , further indicates that the limit value of $q_{\infty}^{C} \quad$ is $\widehat{q}=\lim _{c_{1}} \longrightarrow 0 q_{\infty}^{C}$ $=\left(\mu \varepsilon^{2}\left(a-b c_{0}\right) / 2 b k\left[\phi^{2}+\phi r\right]-\mu^{2} \varepsilon^{2}\right)$. Therefore, according to Proposition 2 and Corollary 2, the operational inefficiency coefficient $c_{1}$ greatly affects the pricing strategy of the brand, which is shown in the following corollary.

Corollary 3. Based on the initial quality level $q_{0}$ and the quality level's limit value $\hat{q}$, the pricing strategies are provided as follows:

(i) When $q_{0} \geq \hat{q}$, the decision maker will implement the skimming pricing strategy for any $c_{1} \in(0, \mu / b)$ (ii) When $0<q_{0}<\hat{q}$, the decision maker will choose the price penetration strategy for $c_{1} \in\left(0, \widehat{c}_{1}\right)$ and implement the price skimming strategy for $c_{1} \in\left(\widehat{c}_{1}, \infty\right)$

From Corollary 3 , it can be found that there is a certain threshold point $\widehat{c}_{1}$ that leads to the shift of pricing strategies. Specifically, when $q_{0}$ is large enough, the pricing strategy is not affected by the operational inefficiency coefficient's change. A relatively large operational inefficiency coefficient will reduce the manufacturer's investment in product innovation, leading to a decline in product quality and consequently a decline in selling prices.

\section{The Optimal Strategies under the Decentralized Scenario}

This paper also studies the manufacturer and the brand trading through a wholesale price contract in a decentralized case. Under this contract, the brand procures products from the manufacturer at a wholesale price $\omega(t)$, and sells it to consumers at a selling price. The superscript " $D$ " is used to signify the decentralized decision. The channel members play a Stackelberg game, where the manufacturer acts as the leader and the brand as a follower. The differential game above can be conceptualized in two stages. In the first stage, the manufacturer sets and announces the design innovation and wholesale price. In the second, reacting to the manufacturer's decisions, the brand determines the selling price. The sequence of the differential game is shown in Figure 1.

The differential game consisting of the manufacturer and brand is described as follows:

$$
\begin{array}{ll} 
& \max _{P 2:} \Pi_{M(t), I(t)}^{D}=\int_{0}^{\infty} e^{-r t}\left\{\left(\omega(t)-C_{V}(t)\right) D(t)-C_{I}(t)\right\} \mathrm{d} t \\
& \max _{p(t)} \Pi_{B}^{D}=\int_{0}^{\infty} e^{-r t}\{(p(t)-\omega(t)) D(t)\} \mathrm{d} t \\
\text { s.t. } & q^{\prime}(t)=\varepsilon I(t)-\phi q(t) .
\end{array}
$$

Let $V_{M}^{D}(q)$ and $V_{B}^{D}(q)$ denote the value functions of the players. The HJB equations of both players are given by

$$
\begin{aligned}
& r V_{M}^{D}(q)=\max _{\omega, I}\left\{\left(\omega-c_{0}-c_{1} q\right)(a-b p+\mu q)-\frac{1}{2} k I^{2}+V_{M}^{D^{\prime}}(\varepsilon I-\phi q)\right\}, \\
& r V_{B}^{D}(q)=\max _{p}\left\{(p-\omega)(a-b p+\mu q)+V_{B}^{D^{\prime}}(\varepsilon I-\phi q)\right\} .
\end{aligned}
$$

The following notations are defined to simplify the expression of the mathematical model: 
The manufacturer offers contract with parameters $I(t)$ and $\omega(t)$
The brand determines the sales price $p(t)$

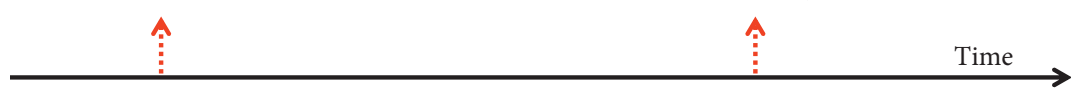

Figure 1: The sequence of events under the decentralized decision.

$$
\begin{aligned}
& \Omega_{2}=\sqrt{\left[(2 \phi b k+r b k)^{2}-b k \varepsilon^{2}\left(\mu-b c_{1}\right)^{2}\right]} \\
& n_{1}=\frac{2 \phi b k+r b k-\Omega_{2}}{2 b \varepsilon^{2}} \\
& n_{2}=\frac{k\left(a-b c_{0}\right)\left(\mu-b c_{1}\right)}{2\left(r b k+\Omega_{2}\right)} .
\end{aligned}
$$

The following proposition characterizes the optimal solutions of players under the decentralized decision.

Proposition 3. With decentralized decision-making, the equilibrium strategies of the manufacturer and brand are given by the following:

$$
\begin{aligned}
& I^{D}(t)=\frac{\varepsilon}{k}\left(n_{1} q(t)+n_{2}\right), \\
& \omega^{D}(t)=\frac{a+b c_{0}+\left(\mu+b c_{1}\right) q(t)}{2 b}, \\
& p^{D}(t)=\frac{3 a+b c_{0}+\left(3 \mu+b c_{1}\right) q(t)}{4 b} .
\end{aligned}
$$

From Proposition 3, similar to Proposition 1, we can observe that the equilibrium strategies increase with the state variable, which indicates that when consumers have a preference for high-quality products, decision makers will increase design efforts and price by improving product quality to maximize profits.

Substituting (18) into the state equation (1) gives

$$
q^{D *}(t)=\left(q_{0}-q_{\infty}^{D}\right) e^{-\eta^{D} t}+q_{\infty}^{D},
$$

where $\eta^{D}=\left(\Omega_{2}^{2}-r^{2} b^{2} k^{2} / 2 b k\left(r b k+\Omega_{2}\right)\right), q_{\infty}^{D}=\left(b k \varepsilon^{2}(\mu-\right.$ $\left.\left.b c_{1}\right)\left(a-b c_{0}\right) / \Omega_{2}^{2}-r^{2} b^{2} k^{2}\right)$ referring to the steady-state quality level. Thus, based on Proposition 3 , the optimal design innovation $I^{D *}(t)$, wholesale price $\omega^{D *}(t)$, and pricing $p^{D *}(t)$ can be presented as the following proposition.

Proposition 4. With decentralized decision-making, the optimal design innovation, wholesale price, and selling price are given by

$$
\begin{aligned}
& I^{D *}(t)=\frac{\varepsilon n_{1}}{k}\left(q_{0}-q_{\infty}^{D}\right) e^{-\eta^{D} t}+I_{\infty}^{D}, \\
& \omega^{D *}(t)=\frac{\left(\mu+b c_{1}\right)}{2 b}\left(q_{0}-q_{\infty}^{D}\right) e^{-\eta^{D} t}+\omega_{\infty}^{D}, \\
& p^{D *}(t)=\frac{\left(3 \mu+b c_{1}\right)}{4 b}\left(q_{0}-q_{\infty}^{D}\right) e^{-\eta^{D} t}+p_{\infty}^{D},
\end{aligned}
$$

where $I_{\infty}^{D}=(\varepsilon / k)\left(n_{1} q_{\infty}^{D}+n_{2}\right), \quad \omega_{\infty}^{D}=\left(a+b c_{0}+\left(\mu+b c_{1}\right)\right.$ $\left.q_{\infty}^{D} / 2 b\right)$, and $p_{\infty}^{D}=\left(3 a+b c_{0}+\left(3 \mu+b c_{1}\right) q_{\infty}^{D} / 4 b\right)$ represent the steady state of design innovation, the wholesale price of goods, and selling price of goods, respectively.

Based on Proposition 4, the profits for the players are as follows:

$$
\begin{aligned}
& \Pi_{M}^{D *}=\frac{n_{1} q_{0}^{2}}{2}+n_{2} q_{0}+n_{3}, \\
& \Pi_{B}^{D *}=\frac{l_{1} q_{0}^{2}}{2}+l_{2} q_{0}+l_{3} .
\end{aligned}
$$

The corresponding equilibrium profit of the ODM supply chain is given by

$$
\Pi_{S C}^{D *}=\Pi_{M}^{D *}+\Pi_{B}^{D *},
$$

where $n_{i}, l_{i}(i=1,2,3)$ are shown in (A.17) and (A.18) in the appendix.

Similar to centralized decision, both the manufacturer and the brand have two pricing strategies, that is, skimming pricing strategy and penetration pricing strategy. The determinant of pricing strategy depends on the relationship between the initial value and the stable value of product quality.

Corollary 4. Compared with the design innovation, quality level, and supply chain's profit values in the decentralized and centralized decisions, we have $I_{\infty}^{C}>I_{\infty}^{D}, q_{\infty}^{C}>q_{\infty}^{D}, \Pi_{S C}^{C}>\Pi_{S C}^{D}$, whereas the selling price is related as follows:

(i) $\left(\mu-b c_{1}\right) \mu \varepsilon^{2} / k<b \phi(r+\phi), p_{\infty}^{C}<p_{\infty}^{D}$

(ii) $\left(\mu-b c_{1}\right) \mu \varepsilon^{2} / k=b \phi(r+\phi), p_{\infty}^{C}=p_{\infty}^{D}$

(iii) $\left(\mu-b c_{1}\right) \mu \varepsilon^{2} / k>b \phi(r+\phi), p_{\infty}^{C}>p_{\infty}^{D}$

This paper defines $\lambda=\left(\mu-b c_{1}\right) \mu \varepsilon^{2} / k$ as the design effectiveness of products to reflect the benefits from investing in the improvement of quality. From Corollary 4, it can be found that there is an intersection between the sales price under the centralized scenario and the sales price under the decentralized scenario. When the design effectiveness is lesser than a certain threshold $b \phi(r+\phi)$, the selling price in the centralized setting is lower than that in the decentralized one. When the design effectiveness of products is larger than a certain threshold $b \phi(r+\phi)$, the selling price in the decentralized setting is lower than that in the centralized one. Also, Corollary 4 shows that the steady-state design innovation, quality level, and supply chain's profit are lower in the decentralized decision compared to those in the centralized decision. Furthermore, Corollary 4 suggests that 
the wholesale price contract in a differential game cannot coordinate the decentralized ODM supply chain. Therefore, it is necessary to design an appropriate contract to improve system efficiency.

\section{Coordination Contract}

How to coordinate the ODM supply chain when considering that product quality changes dynamically with time? Motivated by the coordination method in Zhang et al. [8], this paper provides a two-part tariff contract to coordinate the ODM supply chain. The wholesale price is given by

$$
\omega(t)=C_{V}(t)+\frac{\psi}{D(t)},
$$

where $\psi$ is a positive constant, which is called the coordinating tool, and $D(t)$ is the market demand in formula (4). The superscript " $T$ " is used to signify the coordination contract scenario. Similar to the decentralized scenario, the members of the ODM supply chain play a Stackelberg game, in which the dominant manufacturer acts as the leader and the brand as a follower. Figure 2 shows the sequence of the differential game under coordinating scenario.

Substituting (25) into $((6 a)-(6 c))$ yields the players' profits as follows:

$$
\begin{array}{ll} 
& \max _{I(t)} \Pi_{M}^{T}=\int_{0}^{\infty} e^{-r t}\left\{\psi-C_{I}(t)\right\} \mathrm{d} t \\
\text { P3: } & \max _{p(t)} \Pi_{B}^{T}=\int_{0}^{\infty} e^{-r t}\left\{\left(p(t)-C_{V}(t)\right) D(t)-\psi\right\} \mathrm{d} t \\
\text { s.t. } & q^{\prime}(t)=\varepsilon I(t)-\phi q(t) .
\end{array}
$$
by

The equilibrium profit of the ODM supply chain is given

$$
\Pi_{S C}^{T}=\Pi_{M}^{T}+\Pi_{B}^{T}
$$

The following proposition characterizes the optimal solutions of players under the coordination-contract scenario.

Proposition 5. The strategies and payoffs in the centralized decision scenario $(C)$, decentralized decision $(D)$, and coordination-contract scenario $(T)$ are related as follows:

(i) The optimal design innovation effort of the manufacturer $t, I^{D *}(t)<I^{C *}(t)=I^{T *}(t)$

(ii) The optimal selling price of the brand, $p^{D *}(t)>p^{C *}(t)=p^{T *}(t)$

(iii) The optimal supply chain's profit, $\Pi_{S C}^{D *}<\Pi_{S C}^{C *}=\Pi_{S C}^{T *}$

From Proposition 5, it can be observed that the two-part tariff contract can coordinate the ODM supply chain. The optimal strategies of the coordination-contract scenario are consistent with the optimal solutions of the centralized decision scenario. The result above fully highlights the importance of strategic incentives between the manufacturer and the brand.

Based on Proposition 5, the profits of the players are given as follows:

$$
\begin{aligned}
& \Pi_{M}^{T *}(\psi)=\frac{g_{1} q_{0}^{2}}{2}+g_{2} q_{0}+g_{3}(\psi), \\
& \Pi_{B}^{T *}(\psi)=\frac{h_{1} q_{0}^{2}}{2}+h_{2} q_{0}+h_{3}(\psi) .
\end{aligned}
$$

The supply chain's profit $\Pi_{S C}^{T *}=\Pi_{M}^{T *}(\psi)+\Pi_{B}^{T *}(\psi)=$ $\Pi_{S C}^{C *}$. As observed from formulas (28) and (29), the profits of both members depend on the coordinating tool $\psi$, whereas the channel's profit is independent of $\psi$. In order to ensure that both the manufacturer and the brand participate in the two-part tariff contract, the following two inequalities should be satisfied at the same time:

$$
\begin{aligned}
& \Delta \Pi_{M}=\Pi_{M}^{T *}(\psi)-\Pi_{M}^{D *}=\frac{\psi-\psi_{1}}{r}>0 \\
& \Delta \Pi_{B}=\Pi_{B}^{T *}(\psi)-\Pi_{B}^{D *}=\frac{\psi_{2}-\psi}{r}>0
\end{aligned}
$$

where $\quad \psi_{1}=r\left(\Pi_{M}^{D *}-\Pi_{M}^{T *}(0)\right), \quad \psi_{2}=r\left(\Pi_{B}^{T *}(0)-\Pi_{B}^{D *}\right)$. $\Delta \Pi_{M}$ and $\Delta \Pi_{B}$ represent the extraprofits for the manufacturer and the brand, respectively. And then, we can have the following corollary.

Corollary 5. When $\psi_{1}<\psi<\psi_{2}$, the channel members of the ODM supply chain will choose to participate in the two-part tariff contract.

It can be seen from Proposition 5 and Corollary 5 that when the ODM supply chain is coordinated, the manufacturer needs to set a constant revenue share for each unit of products according to the share of channel cost, and both two players of the ODM supply chain will participate in the implementation of the two-part tariff contract when $\psi$ locates between $\psi_{1}$ and $\psi_{2}$.

This paper introduces a Nash bargaining model $[47,48]$ by using further information, such as the risk preferences of channel members, to get a precise value of $\psi$. The utility functions of the brand and the manufacturer are introduced as follows: 
The manufacturer offers contract with parameters $I(t)$ and $\omega(t)=C_{V}(t)+\psi / D(t)$

$$
\begin{gathered}
\frac{1}{\text { Figure 2: The sequ }} \\
u_{1}\left(\Delta \Pi_{M}\right)=\left(\Delta \Pi_{M}\right)^{\tau_{m}}, \\
u_{2}\left(\Delta \Pi_{B}\right)=\left(\Delta \Pi_{B}\right)^{\tau_{b}},
\end{gathered}
$$

where $\tau_{m}$ and $\tau_{b}$ represent the risk preference coefficients of the players.

The Nash bargaining model is established as follows:

$$
\begin{gathered}
\max _{\Delta \Pi_{M}, \Delta \Pi_{B}} u_{1} u_{2}=\left(\Delta \Pi_{M}\right)^{\tau_{m}}\left(\Delta \Pi_{B}\right)^{\tau_{b}} \\
\text { s.t. } \quad \Delta \Pi_{M}+\Delta \Pi_{B}=\Delta \Pi_{M+B} .
\end{gathered}
$$

The Nash bargaining solutions are as follows:

$$
\begin{aligned}
\Delta \Pi_{B} & =\frac{\tau_{b}}{\tau_{m}+\tau_{b}} \Delta \Pi_{M+B}, \\
\Delta \Pi_{M} & =\frac{\tau_{m}}{\tau_{m}+\tau_{b}} \Delta \Pi_{M+B} .
\end{aligned}
$$

From formula (33), it can be observed that both players split the additional profit in proportion to their risk preference. Based on formula (33), we get the following:

$$
\psi=\frac{\tau_{b}}{\tau_{m}+\tau_{b}} \psi_{2}+\frac{\tau_{m}}{\tau_{m}+\tau_{b}} \psi_{1} .
$$

Note that if $\tau_{m}=\tau_{b}$, both members of the ODM supply chain split the equal extra profit. If $\tau_{m}>\tau_{b}$, the manufacturer can obtain more benefits than the brand. Otherwise, if $\tau_{m}<\tau_{b}$, the brand can extract more benefits.

\section{Illustrative Example}

In this section, we conduct numerical analyses to validate the theoretical results and gain managerial insights. We set market size $a=80$, price sensitivity parameter $b=2$, the initial unit production cost $c_{0}=1$, operational inefficiency coefficient $c_{1}=0.3$, the effect from quality level onto the market size $\mu=1$, the effectiveness of design innovation on the quality level $\varepsilon=1$, design cost coefficient $k=2$, the decay rate of quality level $\phi=0.4$, and discount factor $r=0.2$.

7.1. Comparisons of Optimal Solutions. This paper defines $\lambda=\left(\mu-b c_{1}\right) \mu \varepsilon^{2} / k$ as the design effectiveness of products to reflect the benefits from investing in the improvement of quality. The design effectiveness $\lambda$, as a significant element affecting the channel players' decisions, exerts a great effect on players' profitability and quality level of product. We will pay attention to the impact of the design effectiveness $\lambda$ on the corresponding decisions under centralized and decentralized scenarios. Here, we keep the values of $\varepsilon, b, c_{1}, k$ unchanged and adjust the value of $\mu$ such that $\mu$ varies from
The brand determines the sales price $p(t)$

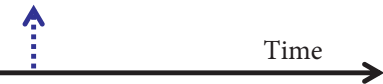

0.6 to 2.5 at a step of 0.1 . Then, the design effectiveness $\lambda$ varies from 0 to 2.37 .

Figure 3 shows that the steady-state selling price of the decentralized decision is larger than the centralized one until $\lambda$ reaches a certain threshold $\tilde{\lambda}$. The point of intersection of two curves $\widetilde{\lambda}=0.716$ with $\tilde{\mu}=1.53$. Afterward, when $\lambda>\widetilde{\lambda}$, the steady-state selling price of decentralized decisionmaking is lower than the centralized one, which is consistent with the results of Corollary 4 . It indicates that centralized decision-making situations do not necessarily lead to a lower selling price because, in a centralized decision-making situation, high-quality products produced with higher innovation efficiency allow the brand to charge higher selling prices. Generally, when consumers have a strong preference for high-quality products, the product with special functions can be sold at a high price.

As can be seen from Figures 4-6, compared with the equilibrium results of the decentralized scenario, the design innovation effort, quality level, and supply chain's profit of the centralized scenario are relatively high. The results are consistent with the result of Corollary 4 . Besides, as design effectiveness improves, the design innovation effort, quality level, and supply chain's profit gap between the two decision-making scenarios also increase. This means that although the balance between centralized decision and decentralized decision increases with the increase of design effectiveness. When faced with high design effectiveness, the improvement of centralized decision is much larger than that of decentralized decision.

\subsection{Sensitivity Analysis}

7.2.1. Impact of the Design Effectiveness on Coordination $(\lambda)$. Given a two-part tariff contract that perfectly coordinates the ODM supply chain, in this subsection, we focus on examining how the design effectiveness $\lambda$ affects the performance of the ODM supply chain. The value of $\mu$ is adjusted from 0.6 to 2.2 at a step of 0.2 . Then, the design effectiveness $\lambda$ varies from 0 to 1.76. According to Proposition 5 and Corollary 5 , we have Figure 7 and Table 2 . When the contract parameter $\psi$ is located between $\psi_{1}$ and $\psi_{2}$, the ODM supply chain can be coordinated by the two-part tariff contract. $\Delta \psi=\psi_{2}-\psi_{1}$ is the span of the feasible region for the coordinating contract. The impact of $\lambda$ on $\psi$ is described in Figure 7, which shows that the range of the contract parameter value is divided by two curves $\psi_{1}$ and $\psi_{2}$ into three regions. Meanwhile, the region above curve $\psi_{1}$ satisfies the condition of $\Pi_{M}^{T}(\psi)>\Pi_{M}^{D}$, ensuring that the manufacturer enjoying higher profit than in the decentralized one. Meanwhile, the region below curve $\psi_{2}$ ensures $\Pi_{B}^{T}(\psi)>\Pi_{B}^{D}$, 


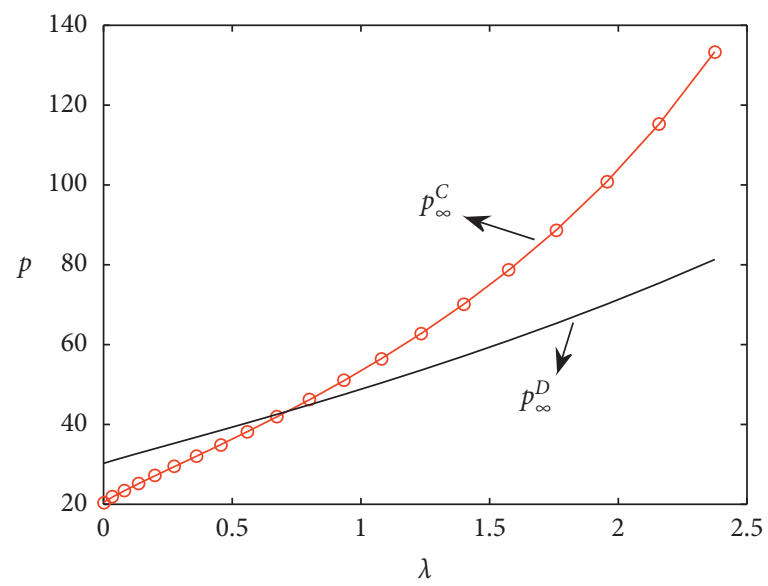

- - Centralized scenario

— Decentralized scenario

Figure 3: Impact of $\lambda$ on selling price.

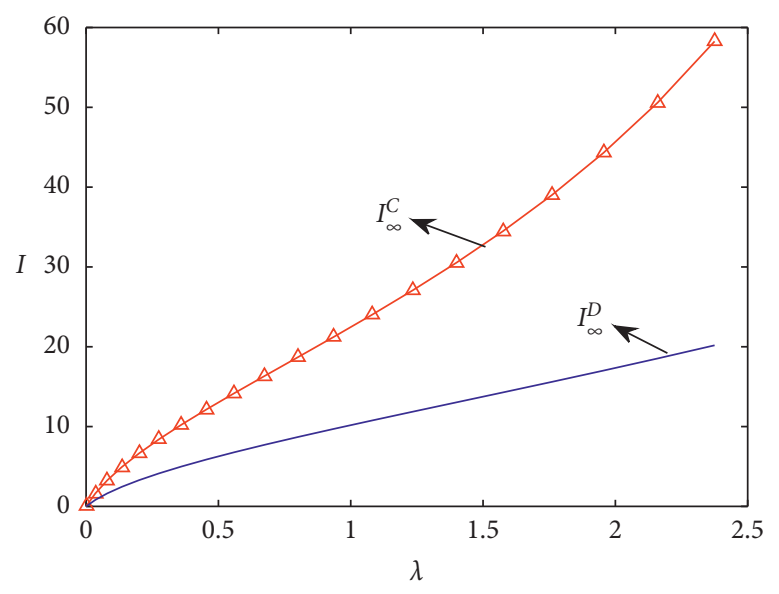

$\triangle$ Centralized scenario

— Decentralized scenario

Figure 4: Impact of $\lambda$ on design innovation.

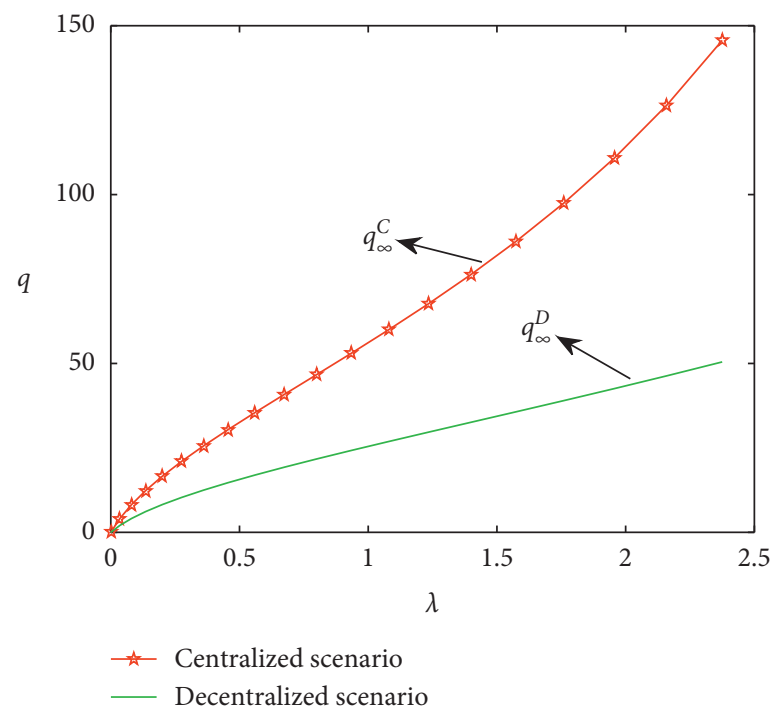

FIGURE 5: Impact of $\lambda$ on quality level. 


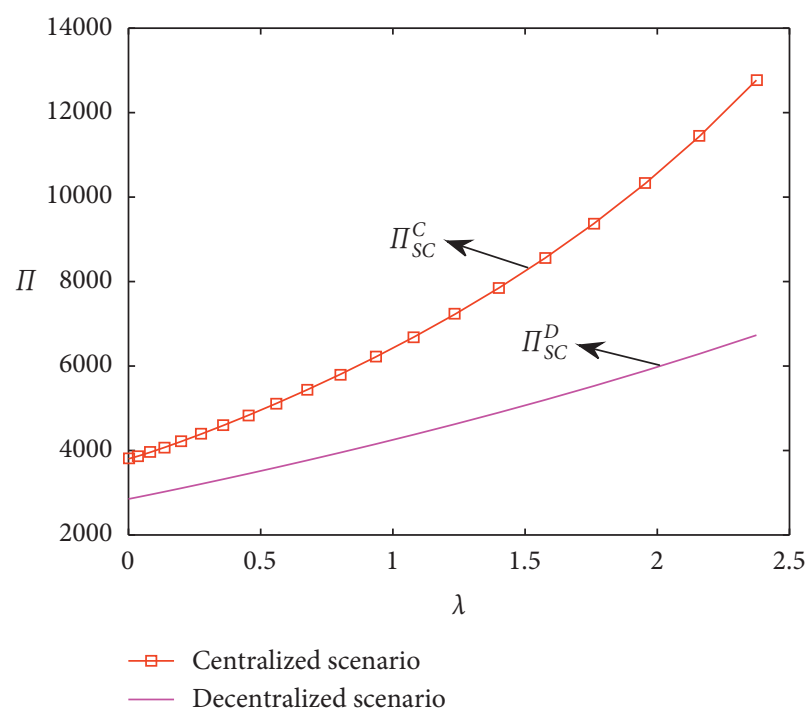

Figure 6: Impact of $\lambda$ on supply chain's profit.

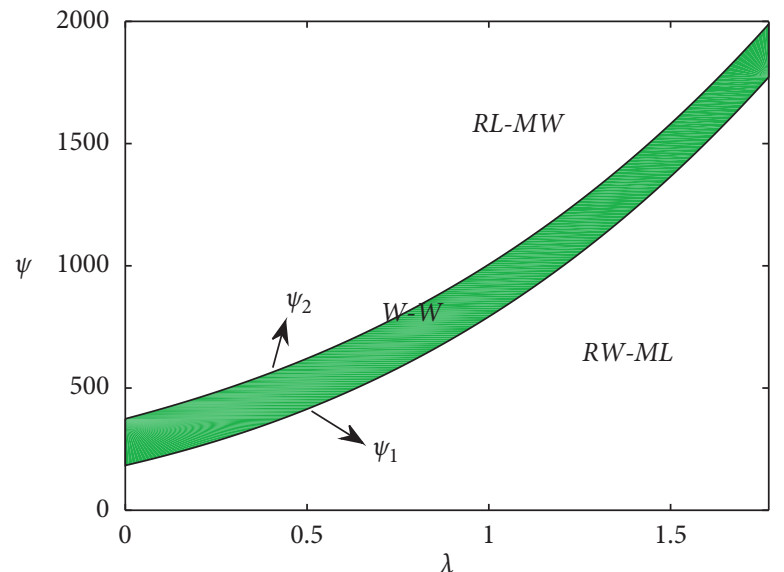

Figure 7: Impact of $\lambda$ on $\psi$.

TABle 2: Impact of the design effectiveness on coordination.

\begin{tabular}{lccccccccc}
\hline$\mu$ & 0.6 & 0.8 & 1 & 1.2 & 1.4 & 1.6 & 1.8 & 2 & 2.2 \\
\hline$\lambda$ & 0.0 & 08.0 & 0.20 & 0.36 & 0.56 & 0.80 & 1.08 & 1.40 & 1.76 \\
$\psi_{1}$ & 190.1 & 208.4 & 255.0 & 334.0 & 453.0 & 624.8 & 870.5 & 1226.4 & 1757.7 \\
$\psi_{2}$ & 380.3 & 403.4 & 454.6 & 538.1 & 661.2 & 836.5 & 1085.0 & 1442.7 & 1974.6 \\
$\Delta \psi$ & 190.1 & 195.0 & 199.6 & 204.1 & 208.1 & 211.7 & 214.5 & 216.3 & 216.9 \\
\hline
\end{tabular}

ensuring that the brand is getting more profit than in the decentralized one. As such, Figure 7 depicts three regions, that is, the brand-lose-manufacturer-win region (RL-MW), brand win-manufacturer-lose region (RW-ML), and winwin region $(\mathrm{W}-\mathrm{W})$. When $\psi$ locates between $\psi_{1}$ and $\psi_{2}$, both members are better off. In addition, from Table 2, it can be observed that the feasible region becomes larger as the design effectiveness $\lambda$ increases. The above results indicate that a larger design effectiveness creates a larger space for the channel members of the ODM supply chain. Manufacturers should make greater efforts to improve the design effectiveness of the products so that the ODM Supply chain can be more easily coordinated.

\subsubsection{Impact of Operational Inefficiency on Coordination} $\left(c_{1}\right)$. The operational inefficiency effect is usually overlooked, but it does indeed exist in the production process for the manufacturers. As an important coefficient characterizing the operational inefficiency effect, $c_{1}$ may play a key 


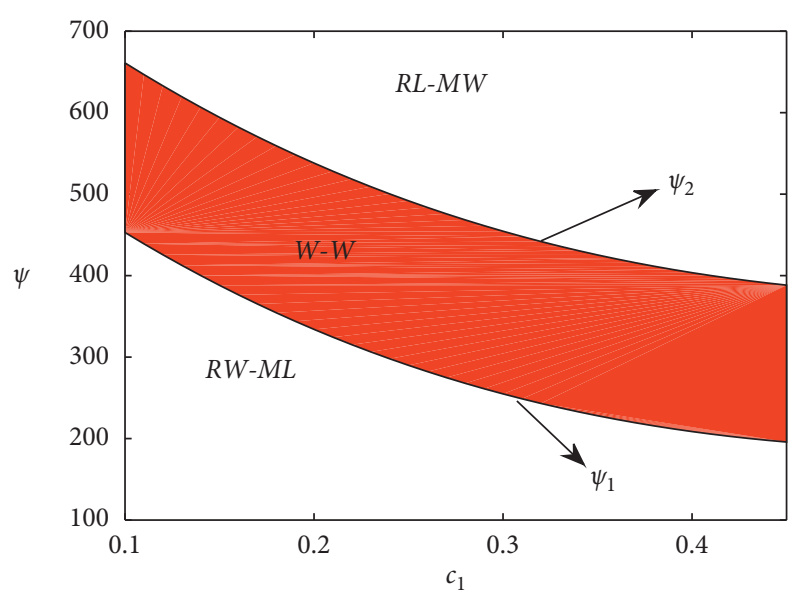

Figure 8: Impact of $c_{1}$ on $\psi$.

TABLE 3: Impact of the operational inefficiency on coordination.

\begin{tabular}{lcccccccc}
\hline$c_{1}$ & 0.10 & 0.15 & 0.20 & 0.25 & 0.30 & 0.35 & 0.40 & 0.45 \\
\hline$\psi_{1}$ & 453.0 & 387.9 & 334.0 & 290.1 & 255.0 & 228.0 & 208.4 & 195.9 \\
$\psi_{2}$ & 661.2 & 594.0 & 538.1 & 491.9 & 454.6 & 425.3 & 403.4 & 388.4 \\
$\Delta \psi$ & 208.1 & 206.1 & 204.1 & 201.9 & 199.6 & 197.3 & 195.0 & 192.6 \\
\hline
\end{tabular}

role in coordination. Figure 8 and Table 3 describe the impact from $c_{1}$ on the contract parameter $\psi$. The plane is also divided into three regions. When $\psi$ locates between $\psi_{1}$ and $\psi_{2}$, the designed contract is able to coordinate the ODM supply chain. From Table 3, we can see that the feasible region between $\psi_{1}$ and $\psi_{2}$ becomes smaller as the operational inefficiency $c_{1}$ increases. The above results indicate that a larger operational inefficiency will provide a smaller degree of flexibility for the channel members to coordinate the ODM supply chain. This is because the operational inefficiency has a negative effect on the optimal solution, and the high operating efficiency effect constitutes an obstacle to innovation investment, which ultimately leads to low energy efficiency and low sales prices.

\section{Conclusions}

Joint dynamic innovation and pricing strategies have largely been overlooked in the ODM supply chain management literature. This paper attempts to fill this gap. We establish an analytical model to examine an ODM supply chain, which consists of one manufacturer and one brand. The manufacturer is responsible for both design and manufacturing of goods and then sells the finished products to end customers through the brand that controls the selling price. The quality level of the product, which is improved by the manufacturer and positively contributes to market demand, drops over time. The dynamics of quality level are introduced in an integrated distribution channel, where both members of the ODM supply chain expect to maximize their respective profits. We then investigate a decentralized channel structure, of which the brand decides on the selling price while the manufacturer sets design innovation and wholesale price.
The optimal operational decisions are derived and compared. A two-part tariff contract is introduced to coordinate the decentralized ODM supply chain.

We summarize our insights and managerial recommendations as follow: (1) in the centralized system, design innovation effort, quality level of goods and supply chain's profit of decentralized decision scenario are lower than those of centralized one, but the selling price relationship in both scenarios depends on the innovation effectiveness. When the innovation efficiency is higher than a certain threshold, the sales price under the centralized decisionmaking scenario is greater than the selling price under the decentralized decision-making scenario. If consumers have a strong preference for high-quality products, manufacturers are advised to increase investment in innovation efficiency to improve product quality. If consumers do not have a strong preference for high-quality products, manufacturers should reduce investment in product innovation. (2) The ODM supply chain can be effectively coordinated by the two-part tariff contract. Therefore, the ODM supply chain members to implement a dynamic transfer pricing strategy is the key to achieving coordination. The upstream and downstream companies in the ODM supply chain should abandon the traditional zero-sum game thinking, and even if they cannot adopt a centralized management model, they should maintain the effectiveness of their cooperation commitments. Because in the cooperative mode, when the negotiation parameters of the contract are in a certain range, the individual profits of the innovation channel members are higher than their respective profits under decentralized decision-making. (3) The degree of risk preference will affect the profit segmentation between the manufacturer and the brand. A positive correlation exists between risk and return: the greater the risk, the higher the potential for profit or loss. The manufacturer and the retailer should distribute the extra profit proportionally to their risk preference.

Our model can be further analyzed from the following extension directions. Although this bilateral monopoly is a standard in the literature, future research can generalize the model presented in this paper by considering the situation of multiple brands or manufacturers. Also, consumer demand for products is affected by random fluctuations in reality. Therefore, in future research, it is meaningful to study the case of random market demand. Last but not least, it would be useful to test our results through qualitative research and case studies.

\section{Appendix}

Proof. of Propositions 1 and 2

The optimization problem of the ODM supply chain is given as follows:

$$
\max _{p(t), I(t)} J_{S C}^{C}=\int_{0}^{\infty} e^{-r t}\left\{\left[p(t)-C_{V}(t)\right] D(t)-C_{I}(t)\right\} \mathrm{d} t .
$$


Let the value function $V_{S C}^{C}(q(t), t)=\max _{p, I} e^{-r t}$ $\int_{t}^{\infty} e^{-r(s-t)}\left\{\left[p(s)-C_{V}(s)\right] D(s)-C_{I}(s)\right\} \mathrm{d} s$.

The ODM supply chain's profit function then is given as follows:

$$
\Pi_{S C}^{C}=\lim _{t \longrightarrow 0} e^{-r t} V_{S C}^{C}(q(t), t)=V_{S C}^{C}\left(q_{0}\right) .
$$

The value function of the ODM supply chain $V_{S C}^{C}(q)$ satisfies the HJB equation as follows:

$$
\begin{aligned}
r V_{S C}^{C}(q)= & \max _{p, I}\left\{\left(p-c_{0}-c_{1} q\right)(a-b p+\mu q)-\frac{1}{2} k I^{2}\right. \\
& \left.+V_{S C}^{C^{\prime}}(\varepsilon I-\phi q)\right\} .
\end{aligned}
$$

Maximization of the formula (A.3) with respect to $I$ and $p$ yields the following:

$$
\begin{aligned}
I^{C} & =\frac{\varepsilon}{k} V_{S C}^{C^{\prime}}, \\
p^{C} & =\frac{a+b c_{0}+\left(\mu+b c_{1}\right) q}{2 b} .
\end{aligned}
$$

Inserting (A.4) on formula (A.3) provides the following:

$$
\begin{aligned}
r V_{S C}^{C}(q)= & \frac{\left(\mu-b c_{1}\right)^{2}}{4 b} q^{2}+\left(V_{S C}^{C^{\prime}} \phi+\frac{\left(a-b c_{0}\right)\left(\mu-b c_{1}\right)}{2 b}\right) q \\
& +\frac{\left(a-b c_{0}\right)^{2}\left(\varepsilon V_{S C}^{C^{\prime}}\right)^{2}}{8 k b} .
\end{aligned}
$$

Note that $V_{S C}^{C}(q)$ is the value function for the maximization problem $\mathrm{P} 1$. We assume that the value function of the ODM supply chain is linear and given by

$$
V_{S C}^{C}(q)=\frac{f_{1} q^{2}}{2}+f_{2} q+f_{3}
$$

and it follows from (A.6) that

$$
V_{S C}^{C^{\prime}}=f_{1} q+f_{2} .
$$

Substituting (A.6) and (A.7) into (A.5), we can obtain the expressions of $f_{1}, f_{2}$, and $f_{3}$, which are given in Proposition 1.

Substituting $f_{1}, f_{2}$, and $f_{3}$ into (A.4), we get the expressions of the design innovation investment and optimal selling price strategies which are shown in Proposition 2.

Proof. of Propositions 3 and 4

The optimization problem of the supplier is given as follows:

$$
\max _{p(t)} \Pi_{B}^{D}=\int_{0}^{\infty} e^{-r t}\{(p(t)-\omega(t)) D(t)\} \mathrm{d} t .
$$

Let the value function $V_{B}^{D}(q(t), t)=$ $\max _{p} e^{-r t} \int_{t}^{\infty} e^{-r(s-t)}\{[p(s)-\omega(s)] D(s)\} \mathrm{d} s$. The optimal profit function of the brand is given as follows:

$$
\Pi_{B}^{D}=\lim _{t \longrightarrow 0} e^{-r t} V_{B}^{D}(q(t), t)=V_{B}^{D}\left(q_{0}\right) .
$$

Similarly, let $V_{M}^{D}(q(t), t)$ denote the value function of the manufacturer.

The optimal profit function of the manufacturer is as follows:

$$
\Pi_{M}^{D}=\lim _{t \longrightarrow 0} e^{-r t} V_{M}^{D}(q(t), t)=V_{M}^{D}\left(q_{0}\right) .
$$

The brand's HJB is as follows:

$$
r V_{B}^{D}(q)=\max _{p}\left\{(p-\omega)(a-b p+\mu q)+V_{B}^{D^{\prime}}(\varepsilon I-\phi q)\right\} .
$$

Maximization of the formula (A.11) with respect to $p$ yields the following:

$$
p=\frac{a+b \omega+\mu q}{2 b}
$$

Similarly, the manufacturer's HJB equation is as follows:

$$
r V_{M}^{D}(q)=\max _{\omega, I}\left\{\left(\omega-c_{0}-c_{1} q\right)(a-b p+\mu q)-\frac{1}{2} k I^{2}+V_{M}^{D^{\prime}}(\varepsilon I-\phi q)\right\} .
$$

Maximization of the formula (A.13) with respect to $\omega$ and $I$ yields the following:

$$
\begin{aligned}
\omega^{D} & =\frac{a+b c_{0}+\left(\mu+b c_{1}\right) q}{2 b}, \\
I^{D} & =\frac{\varepsilon}{k} V_{M}^{D^{\prime}} .
\end{aligned}
$$
price,
Substituting (A.14) into (A.12), we can obtain the selling

$$
p^{D}=\frac{3 a+b c_{0}+\left(3 \mu+b c_{1}\right) q}{4 b}
$$

Substituting (A.14) and (A.15) into HJB equations (A.11) and (A.13) and assuming the following quadratic equations,

$$
\begin{aligned}
& V_{M}^{D}(q)=\frac{n_{1} q^{2}}{2}+n_{2} q+n_{3}, \\
& V_{B}^{D}(q)=\frac{l_{1} q^{2}}{2}+l_{2} q+l_{3},
\end{aligned}
$$


in which $n_{1}, n_{2}, n_{3}$ and $l_{1}, l_{2}, l_{3}$ and are constants. We substitute $V_{M}^{D}(q), V_{B}^{D}(q)$ from (A.16), as well as their derivatives, into (A.11) and (A.13), and collect terms corresponding to $q$. By solving the algebraic equations, we have the following:

$$
\begin{aligned}
& \left\{\begin{array}{l}
n_{1}=\frac{b k(2 \phi+r)-\Omega_{2}}{2 b \varepsilon^{2}}, \\
n_{2}=\frac{k\left(a-b c_{0}\right)\left(\mu-b c_{1}\right)}{2\left(r b k+\Omega_{2}\right)}, \\
n_{3}=\frac{\left(a-b c_{0}\right)^{2}\left[\left(r b k+\Omega_{2}\right)^{2}+b k \varepsilon^{2}\left(\mu-b c_{1}\right)^{2}\right]}{8 b r\left(r b k+\Omega_{2}\right)^{2}}, \\
l_{1}=\frac{k\left(\mu-b c_{1}\right)^{2}}{8 \Omega_{2}}, \\
l_{2}=\frac{k\left(a-b c_{0}\right)\left(\mu-b c_{1}\right)\left[b k \varepsilon^{2}\left(\mu-b c_{1}\right)^{2}+2 \Omega_{2}\left(r b k+\Omega_{2}\right)\right]}{8 \Omega_{2}\left(r b k+\Omega_{2}\right)^{2}}, \\
l_{3}=\frac{\left(a-b c_{0}\right)^{2}\left(\Omega_{2}\left(r b k+\Omega_{2}\right)\right)\left[\left(r b k+\Omega_{2}\right)^{2}+2 b k \varepsilon^{2}\left(\mu-b c_{1}\right)^{2}\right]+b^{2} k^{2} \varepsilon^{4}\left(\mu-b c_{1}\right)^{4}}{16 r b \Omega_{2}\left(r b k+\Omega_{2}\right)^{3}} .
\end{array}\right.
\end{aligned}
$$

Substituting (A.17) and (A.18) into (A.16), we get the expressions of the optimal design innovation, wholesale price, and selling price strategies shown in Propositions 3 and 4 .

Proof. of Proposition 5

The value function of the brand is $V_{B}^{T}(q(t), t)=\max$ ${ }_{p} e^{-r t} \int_{t}^{\infty} e^{-r(s-t)}\{[p(s)-c(s)][a-b p(s)+\mu q(s)-\psi]\} \mathrm{d} s$. follows:

The optimal profit function of the brand is given as

$$
\Pi_{B}^{T}=\lim _{t \longrightarrow 0} e^{-r t} V_{B}^{T}(q(t), t)=V_{B}^{T}\left(q_{0}\right)
$$

Similarly, let $V_{M}^{D}(q(t), t)$ denote the value function of the manufacturer. The manufacturer's profit function is given by the following:

$$
\Pi_{M}^{T}=\lim _{t \rightarrow 0} e^{-r t} V_{M}^{T}(q(t), t)=V_{M}^{T}\left(q_{0}\right) .
$$

The optimal profit function of the ODM supply chain is given by the following:

$$
\Pi_{S C}^{T}=\lim _{t \longrightarrow 0} e^{-r t} V_{S C}^{T}(q(t), t)=V_{S C}^{T}\left(q_{0}\right) .
$$

The brand's HJB is as follows:

$$
r V_{B}^{T}(q)=\max _{p}\left\{\left(p-c_{0}-c_{1} q\right)(a-b p+\mu q)-\psi+V_{B}^{T}(\varepsilon I-\phi q)\right\} .
$$

Maximization of the formula (A.22) with respect to $p$ yields the following:

$$
p^{T}=\frac{a+b c_{0}+\left(\mu+b c_{1}\right) q}{2 b} .
$$

The manufacturer's HJB equation can be specified as follows:

$$
r V_{M}^{T}(q)=\max _{I}\left\{\left(p-c_{0}-c_{1} q\right)(a-b p+\mu q)-\frac{1}{2} k I^{2}+V_{M}^{T}(\varepsilon I-\phi q)\right\} .
$$

Maximization of the formula (A.24) with respect to $I$ yields the following:

$$
I^{T}=\frac{\varepsilon}{k} V_{M}^{T^{\prime}}
$$

Substituting (A.23) and (A.25) into HJB equations (A.22) and (A.24) and assuming the following quadratic equations,

$$
\begin{aligned}
& V_{M}^{T}(q)=\frac{g_{1} q^{2}}{2}+g_{2} q+g_{3}, \\
& V_{B}^{T}(q)=\frac{h_{1} q^{2}}{2}+h_{2} q+h_{3}, \\
& V_{S C}^{T}(q)=\frac{z_{1} q^{2}}{2}+z_{2} q+z_{3},
\end{aligned}
$$

in which $g_{1}, g_{2}, g_{3}, h_{1}, h_{2}, h_{3}, z_{1}, z_{2}$, and $z_{3}$ are constants.

We substitute $V_{M}^{T}(q), V_{B}^{T}(q)$ from (A.26), as well as their derivatives, into (A.22) and (A.24), and collect terms corresponding to $q$. By solving the algebraic equations, we have the following: 


$$
\left\{\begin{array}{l}
g_{1}=-\frac{\left[b k(2 \phi+r)-\Omega_{1}\right]^{2}}{4 \varepsilon^{2} b \Omega_{1}}, \\
g_{2}=\frac{k\left(\Omega_{1}^{2}-b^{2} h^{2}(2 \phi+r)^{2}\right)\left(a-b c_{0}\right)\left(\mu-b c_{1}\right)}{2 \Omega_{1}\left(r b k+\Omega_{1}\right)^{2}}, \\
g_{3}=\frac{\psi}{r}+\frac{\varepsilon^{2}\left(a-b c_{0}\right)\left(\mu-b c_{1}\right)}{r\left(r b k+\Omega_{1}\right)} g_{2}-\frac{k \varepsilon^{2}\left(a-b c_{0}\right)^{2}\left(\mu-b c_{1}\right)^{2}}{2 r\left(r b k+\Omega_{1}\right)^{2}} \\
h_{1}=\frac{k\left(\mu-b c_{1}\right)^{2}}{2 \Omega_{1}}, \\
z_{3}=f_{3}, \quad \begin{array}{l}
f_{2}=\frac{k\left(a-b c_{0}\right)\left(\mu-b c_{1}\right)\left[b k \varepsilon^{2}\left(\mu-b c_{1}\right)^{2}+\Omega_{1}\left(r b k+\Omega_{1}\right)\right]}{\Omega_{1}\left(r b k+\Omega_{1}\right)^{2}} \\
z_{3}=\frac{\varepsilon^{2}\left(a-b c_{0}\right)\left(\mu-b c_{1}\right)}{r\left(r b k+\Omega_{1}\right)} h_{2}+\frac{\left(a-b c_{0}\right)^{2}}{4 r b}-\frac{\psi}{r},
\end{array}
\end{array}\right.
$$

Consequently, $I^{T *}=I^{C *}, p^{T *}=p^{C *}, q^{T *}=q^{C *}$, and $V_{S C}^{T}\left(q_{0}\right)=V_{S C}^{C}\left(q_{0}\right)$. These equilibrium strategies are the same as centralized solutions.

\section{Data Availability}

The raw/processed data required to reproduce these findings cannot be shared at this time as the data also form part of an ongoing study.

\section{Conflicts of Interest}

The author declares no conflicts of interest.

\section{Acknowledgments}

This work was supported by the Fundamental Research Funds for the Shanghai Polytechnic University (EGD20XQD13) and the Fundamental Research Funds for Shanghai Teacher's Union of China (2021GHL04).

\section{References}

[1] P. Romano and A. Vinelli, "Quality management in a supply chain perspective," International Journal of Operations \& Production Management, vol. 21, no. 4, 2001.

[2] M. A. Stanko and R. J. Calantone, "Controversy in innovation outsourcing research: review, synthesis and future directions," R\&D Management, vol. 41, no. 1, pp. 8-20, 2011.
[3] Q. Feng and L. X. Lu, "Design outsourcing in a differentiated product market: the role of bargaining and scope economies," SSRN Electronic Journal, Article ID 2986185, 2010.

[4] Q. Feng and L. Lu, "Outsourcing design to asia," Managing Supply Chains on the Silk Road, CRC Press, Boca Raton, FL, USA, pp. 169-184, 2011.

[5] C. Lin, C. H. Kuei, and K. W. Chai, "Identifying critical enablers and pathways to high performance supply chain quality management," International Journal of Operations \& Production Management, vol. 33, no. 3, 2013.

[6] R. Gaspar and D. Antunes, "Energy efficiency and appliance purchases in Europe: consumer profiles and choice determinants," Energy Policy, vol. 39, no. 11, pp. 7335-7346, 2011.

[7] N. Zhou, D. Fridley, M. McNeil et al., "Analysis of potential energy saving and $\mathrm{CO}_{2}$ emission reduction of home appliances and commercial equipments in China," Energy Policy, vol. 39, no. 8, pp. 4541-4550, 2011.

[8] Q. Zhang, J. Zhang, and W. Tang, "Coordinating a supply chain with green innovation in a dynamic setting," $4 O R$, vol. 15, no. 2, pp. 133-162, 2017.

[9] J. Wang and H. Shin, "The impact of contracts and competition on upstream innovation in a supply chain," Production and Operations Management, vol. 24, no. 1, pp. 134-146, 2015.

[10] B. Shen, Q. Li, C. Dong, and V. Quan, "Design outsourcing in the fashion supply chain: OEM versus ODM," Journal of the Operational Research Society, vol. 67, no. 2, pp. 259-268, 2016.

[11] E. L. Plambeck and T. A. Taylor, "Sell the plant? The impact of contract manufacturing on innovation, capacity, and profitability," Management Science, vol. 51, no. 1, pp. 133-150, 2005.

[12] A. V. Iyer, L. B. Schwarz, and S. A. Zenios, "A principal-agent model for product specification and production," Management Science, vol. 51, no. 1, pp. 106-119, 2005. 
[13] V. Deshpande, L. B. Schwarz, M. J. Atallah, M. Blanton, and K. B. Frikken, "Outsourcing manufacturing: secure pricemasking mechanisms for purchasing component parts," Production and Operations Management, vol. 20, no. 2, pp. 165-180, 2011.

[14] M. Cakanyıldırım, Q. Feng, X. Gan, and S. P. Sethi, "Contracting and coordination under asymmetric production cost information," Production and Operations Management, vol. 21, no. 2, pp. 345-360, 2012.

[15] Y. Wang, B. Niu, and P. Guo, "On the advantage of quantity leadership when outsourcing production to a competitive contract manufacturer," Production and Operations Management, vol. 22, no. 1, pp. 104-119, 2013.

[16] F. El Ouardighi and K. Kogan, "Dynamic conformance and design quality in a supply chain: an assessment of contracts' coordinating power," Annals of Operations Research, vol. 211, no. 1, pp. 137-166, 2013.

[17] G. Liu, J. Zhang, and W. Tang, "Strategic transfer pricing in a marketing-operations interface with quality level and advertising dependent goodwill," Omega, vol. 56, pp. 1-15, 2015.

[18] K. Kogan and C. S. Tapiero, Supply Chain Games: Operations Management and Risk Valuation, Springer Science \& Business Media, Berlin, Germany, 2007.

[19] N. Economides, "Quality choice and vertical integration," International Journal of Industrial Organization, vol. 17, no. 6, pp. 903-914, 1999.

[20] T. F. Bresnahan and P. C. Reiss, "Dealer and manufacturer margins," The RAND Journal of Economics, vol. 16, no. 2, pp. 253-268, 1985.

[21] G. P. Cachon and M. A. Lariviere, "Supply chain coordination with revenue-sharing contracts: strengths and limitations," Management Science, vol. 51, no. 1, pp. 30-44, 2005.

[22] B. Niu, Y. Liu, L. Chen, and P. Ji, "Outsource to an OEM or an ODM? Profitability and sustainability analysis of a fashion supply chain," Journal of Systems Science and Systems Engineering, vol. 27, no. 4, pp. 399-416, 2018.

[23] Y. Wei and T.-M. Choi, "Mean-variance analysis of supply chains under wholesale pricing and profit sharing schemes," European Journal of Operational Research, vol. 204, no. 2, pp. 255-262, 2010.

[24] C. X. Wang and S. Webster, "channel coordination for a supply chain with a risk-neutral manufacturer and a lossaverse retailer," Decision Sciences, vol. 38, no. 3, pp. 361-389, 2007.

[25] S.-D. Wang, Y.-W. Zhou, J. Min, and Y.-G. Zhong, "Coordination of cooperative advertising models in a one-manufacturer two-retailer supply chain system," Computers \& Industrial Engineering, vol. 61, no. 4, pp. 1053-1071, 2011.

[26] Q. Wang, B. Chu, J. Wang, and Y. Kumakiri, "Risk analysis of supply contract with call options for buyers," International Journal of Production Economics, vol. 139, no. 1, pp. 97-105, 2012.

[27] C. H. Lee, B.-D. Rhee, and T. C. E. Cheng, "Quality uncertainty and quality-compensation contract for supply chain coordination," European Journal of Operational Research, vol. 228, no. 3, pp. 582-591, 2013.

[28] T. Xiao, T.-M. Choi, and T. C. E. Cheng, "Optimal variety and pricing decisions of a supply chain with economies of scope," IEEE Transactions on Engineering Management, vol. 62, no. 3, pp. 411-420, 2015.

[29] S. Deng and C. A. Yano, "Designing supply contracts considering profit targets and risk," Production and Operations Management, vol. 25, no. 7, pp. 1292-1307, 2016.
[30] S. Chen, H. Lee, and K. Moinzadeh, "Supply chain coordination with multiple shipments: the optimal inventory subsidizing contracts," Operations Research, vol. 64, no. 6, pp. 1320-1337, 2016.

[31] R. Yan and Z. Cao, "Product returns, asymmetric information, and firm performance," International Journal of Production Economics, vol. 185, pp. 211-222, 2017.

[32] Y. Zhao, T.-M. Choi, T. C. E. Cheng, and S. Wang, "Supply option contracts with spot market and demand information updating," European Journal of Operational Research, vol. 266, no. 3, pp. 1062-1071, 2018.

[33] J. Vörös, "The dynamics of price, quality and productivity improvement decisions," European Journal of Operational Research, vol. 170, no. 3, pp. 809-823, 2006.

[34] P. De Giovanni, "Quality improvement vs. advertising support: which strategy works better for a manufacturer?" European Journal of Operational Research, vol. 208, no. 2, pp. 119-130, 2011.

[35] P. De Giovanni and G. Zaccour, "A two-period game of a closed-loop supply chain," European Journal of Operational Research, vol. 232, no. 1, pp. 22-40, 2014.

[36] S. Karray, "Cooperative promotions in the distribution channel,” Omega, vol. 51, pp. 49-58, 2015.

[37] Q. Chen, Q. Xu, and W. Wang, "Optimal policies for the pricing and replenishment of fashion apparel considering the effect of fashion level," Complexity, vol. 2019, Article ID 9253605, 12 pages, 2019.

[38] F. Lu, J. Zhang, and W. Tang, "Wholesale price contract versus consignment contract in a supply chain considering dynamic advertising," International Transactions in Operational Research, vol. 26, no. 5, pp. 1977-2003, 2019.

[39] G. Xie, W. Yue, W. Liu, and S. Wang, "Risk based selection of cleaner products in a green supply chain," Pacific Journal of Optimization, vol. 8, no. 3, pp. 473-484, 2012.

[40] X. Pan and S. Li, "Dynamic optimal control of processproduct innovation with learning by doing," European Journal of Operational Research, vol. 248, no. 1, pp. 136-145, 2016.

[41] R. Chenavaz, "Dynamic pricing, product and process innovation," European Journal of Operational Research, vol. 222, no. 3, pp. 553-557, 2012.

[42] L. Chen and E. L. Plambeck, "Dynamic inventory management with learning about the demand distribution and substitution probability," Manufacturing \& Service Operations Management, vol. 10, no. 2, pp. 236-256, 2008.

[43] A. Şen and A. X. Zhang, "Style goods pricing with demand learning," European Journal of Operational Research, vol. 196, no. 3, pp. 1058-1075, 2009.

[44] V. F. Araman and R. Caldentey, "Dynamic pricing for nonperishable products with demand learning," Operations Research, vol. 57, no. 5, pp. 1169-1188, 2009.

[45] S. Jørgensen and G. Zaccour, "A survey of game-theoretic models of cooperative advertising," European Journal of Operational Research, vol. 237, no. 1, pp. 1-14, 2014.

[46] A. Chutani and S. P. Sethi, "Optimal advertising and pricing in a dynamic durable goods supply chain," Journal of Optimization Theory and Applications, vol. 154, no. 2, pp. 615-643, 2012.

[47] J. F. Nash Jr, "The bargaining problem," Econometrica, Journal of the Econometric Society, vol. 18, no. 2, pp. 155-162, 1950.

[48] J. Xie and J. C. Wei, "Coordinating advertising and pricing in a manufacturer-retailer channel," European Journal of Operational Research, vol. 197, no. 2, pp. 785-791, 2009. 